\title{
CRIATIVIDADE E TECNOLOGIAS DIGITAIS NA EDUCAÇÃO EM TEMPOS DE PANDEMIA
}

Tharcila de Abreu Almeida

Professora na Fundação Municipal de Educação de Niterói https://orcid.org/0000-0002-7429-0421

Andrea Verbena Clementino Rodrigues Barbosa

Secretaria Estadual de Educação do Distrito Federal https://orcid.org/0000-0002-3957-9705

\section{Elaine do Nascimento Mendes}

Secretaria Municipal de Educação do Rio de Janeiro https://orcid.org/0000-0001-7040-9539

\section{Luciana dos Santos}

Professora na Secretaria Estadual de Educação do Estado do Rio de Janeiro https://orcid.org/0000-0003-4675-1769

\section{Ana Paula Legey de Siqueira}

Professora no Centro Universitário UniCarioca / Pesquisadora Colaboradora na área de Divulgação Científica no Instituto de Engenharia Nuclear / Doutora em Divulgação Científica (IEN/CNEN) https://orcid.org/0000-0002-9056-9844

\section{Luciane Medeiros de Souza Conrado}

Pesquisadora e Professora no Centro Universitário UniCarioca / Cientista Social (UFRJ) / Mestre em Ciência da Arte (UFF) / Doutora em Letras (Linguística - Estudos das Linguagens - UFF) https://orcid.org/0000-0002-1487-5401

\section{Victor Gonçalves Glória Freitas}

CEO na AresVR. Professor no Centro Universitário Carioca. Doutor em Engenharia Nuclear pela COPPE/UFRJ. Mestre em Engenharia de Reatores pelo Instituto de Engenharia Nuclear. http://orcid.org/0000-0002-0154-606X

\section{Bianca Maria Rêgo Martins \\ Professora no Centro Universitário UniCarioca https://orcid.org/0000-0001-7550-2775}

\author{
Alessandro Jatobá \\ Analista de Gestão em Saúde no Centro de Estudos Estratégicos da FIOCRUZ. Professor no Centro \\ Universitário Carioca. Doutor em Engenharia de Produção COPPE/UFRJ \\ https://orcid.org/0000-0002-7059-6546
}




\section{RESUMO}

O presente artigo, desenvolvido em uma disciplina de Interculturalidade por alunos do Mestrado Profissional de um Centro Universitário do Rio de Janeiro, tem como objetivo refletir a importância da criatividade e das tecnologias digitais na Educação, sendo a mesma de primordial necessidade a ser desenvolvida e utilizada pelos docentes e discentes nesse momento de reinvenção perante o novo momento que estamos vivendo com a pandemia da Covid-19. A metodologia utilizada foi uma pesquisa exploratória, descritiva, de revisão teórica simples, em bibliografias com eixo voltado para a criatividade e tecnologias digitais, relevantes à prática tanto do professor quanto do aluno, embasada em autores como Gardner, Moran, Saturnino de La Torre, Torrance, artigos que corroboram com o tema, na Base Nacional Comum Curricular e no Relatório para a UNESCO da Comissão Internacional sobre Educação para o século XXI. Concluiu-se que a criatividade é de grande importância para a educação e que o estímulo da mesma, por meio das tecnologias digitais, é de grande aplicabilidade e fundamental para a Educação.

Palavras-chave: criatividade; educação; tecnologias digitais; pandemia.

\section{CREATIVITY AND DIGITAL TECHNOLOGIES IN EDUCATION IN PANDEMIC TIMES}

\section{ABSTRACT}

This article, developed in a discipline of Interculturality by students of the Professional Master's Degree at a University Center in Rio de Janeiro, aims to reflect the importance of creativity and digital technologies in Education, which are essential to be developed and used. by professors and students in this moment of reinvention in the face of the new moment we are living with the Covid-19 pandemic. The methodology used was an exploratory, descriptive research, with a simple theoretical review, in bibliographies with an axis focused on creativity and digital technologies, relevant to the practice of both the teacher and the student, based on authors such as Gardner, Moran, Saturnino de La Torre, Torrance, articles that corroborate the theme, in the Common National Curriculum Base and in the Report to UNESCO of the International Commission on Education for the 21st Century. It was concluded that creativity is of great importance for education and that its stimulation, through digital technologies, is of great applicability and fundamental for education.

Keywords: creativity; education; digital technologie; pandemic

\section{CREATIVIDAD Y TECNOLOGÍAS DIGITALES EN LA EDUCACIÓN EN TIEMPOS DE PANDEMIA}

\section{RESUMEN}

Este artículo, desarrollado en una disciplina de Interculturalidad por estudiantes de la Maestría Profesional en un Centro Universitario de Río de Janeiro, tiene como objetivo reflejar la importancia de la creatividad y las tecnologías digitales en la Educación, las cuales son fundamentales para ser desarrolladas y utilizadas por los profesores $y$ 
estudiantes en este momento de reinvención ante al nuevo momento que estamos viviendo con la pandemia de Covid-19. La metodología utilizada fue una investigación exploratoria, descriptiva, con una simple revisión teórica, en bibliografías con un eje centrado en la creatividad y las tecnologías digitales, relevantes para la práctica tanto del docente como del alumno, a partir de autores como Gardner, Moran, Saturnino de La Torre, Torrance, artículos que corroboran el tema, en la Base Curricular Nacional Común y en el Informe a la UNESCO de la Comisión Internacional de Educación para el Siglo XXI. Se concluyó que la creatividad es de gran importancia para la educación y que su estimulación, a través de las tecnologías digitales, es de gran aplicabilidad y fundamental para la educación.

Palabras clave: creatividad; educación; tecnologías digitales; pandemia.

\section{INTRODUÇÃO}

O mundo atual vive um momento sem precedentes na história da humanidade, com a existência da pandemia COVID-19 (Coronavirus disease 2019), nos exigindo o desenvolvimento de diversas habilidades para lidarmos com diferentes demandas da sociedade, principalmente no que tange à educação.

A pandemia Covid-19 nos trouxe a necessidade de nos reinventarmos enquanto professores e colocarmos em prática nosso potencial criativo para que pudéssemos afetar positivamente nossos alunos, buscando também criar neles habilidades importantes para seu desenvolvimento. Ser criativo tornou-se pressuposto fundamental para a prática docente neste tempo atual, assim como para os discentes.

Neste contexto, o presente artigo busca refletir o papel da criatividade, propondo repensar que um professor criativo vai muito além de fazer uma aula diferente, passa também pelo caminho de se adaptar às diversas novas situações que surgem dia após dia e que são muitas vezes encaradas como motivo de distração, como acontece com as novas tecnologias digitais, cabendo a nós, enquanto educadores, fazer dessas situações meios de aprendizagem e este é o grande motivo de nos tornarmos a cada dia mais criativos.

Em meio a esse cenário, corroborado pelo Relatório para a UNESCO da Comissão Internacional sobre Educação para o século XXI (2010, p. 14), "a educação deve, portanto, adaptar-se constantemente a essas mudanças da sociedade, sem negligenciar as vivências, os saberes básicos e os resultados da experiência humana".

Desse modo, em um primeiro momento refletiremos através de pesquisa exploratória, descritiva, baseada em uma revisão teórica simples, a importância da criatividade e das tecnologias digitais para as práticas docentes e discentes no período de pandemia da Covid-19. Em seguida, faremos uma análise dos autores e artigos relacionados para auxiliar de forma significativa nas reflexões das práticas educativas e 0 uso das tecnologias digitais na Educação, registrando também as contribuições da disciplina Interculturalidade para o despertar de nosso potencial criador, concluindo assim a importância da criatividade e o quanto estimular as atividades que despertem o ser criativo de cada um dos docentes e discentes é uma habilidade que deve ser desenvolvida no processo ensino-aprendizagem.

Destacamos ainda a importância do curso de Mestrado Profissional de um Centro Universitário, onde tivemos na disciplina de Interculturalidade oportunidades de desenvolvermos novas habilidades de maneira engajadora tendo em vista a forma criativa de como as atividades nos foram propostas aliadas às novas tecnologias, estimulando também a nossa própria criatividade, o que nos fez refletir e analisar mais profundamente o estudo do tema. 


\section{METODOLOGIA}

A metodologia utilizada para esse estudo foi pesquisa exploratória, descritiva, de revisão teórica simples, em que se buscou, em bancos de dados da internet, bibliografias que abordam a criatividade e as tecnologias digitais, assim como artigos científicos que corroboram com o tema. Esse tipo de pesquisa, de acordo com Gil (2010, p. 24) "consiste em pesquisa bibliográfica porque se baseou em materiais já publicados, compostos especialmente por livros, revistas, artigos científicos, tese e por informações especializadas em sites".

Esse tipo de pesquisa, de acordo com Minayo (2001, p. 53) "coloca frente a frente os desejos do pesquisador e os autores envolvidos em seu horizonte de interesse". Assim, após as aulas ministradas na disciplina Interculturalidade, manifestamos nossa pretensão em nos aprofundarmos mais pelo tema que nos despertou bastante curiosidade, resultando na busca por mais conhecimentos sobre o assunto, promovendo o diálogo entre criatividade e tecnologias digitais, bem como eles poderão ser aplicados e vivenciados no cotidiano escolar.

De acordo com Gil (2010) a pesquisa descritiva objetiva a descrição das características de um fato ou indivíduos. Desse modo, após revisão teórica, faremos uma análise por meio de pesquisa descritiva, de quanto a disciplina Interculturalidade contribuiu para esse momento de reinvenção de nossas práticas pedagógicas, registrando sua importância para o despertar de nosso ser criativo.

\section{MARCO TEÓRICO: CRIATIVIDADE E EDUCAÇÃO}

\subsection{A criatividade como competência docente e discente}

A criatividade é uma característica importante da personalidade humana, sendo uma das competências socioemocionais propostas pela Base Nacional Comum Curricular (BNCC, 2017). De acordo com este documento norteador da Educação Básica, o desenvolvimento do pensamento criativo dos alunos levá-los-á a buscar soluções inovadoras para resolução de problemas. Assim, buscarmos soluções em meio ao momento atual que estamos vivenciando com a pandemia da Covid-19 tornou-se imprescindível.

A fim de compreendermos melhor o que seja a criatividade, buscamos na literatura algumas definições para a mesma. De acordo com Cavallo et al. (2016) mesmo no campo da pesquisa científica, criatividade ainda é um conceito vago na literatura, sendo geralmente definida como um conjunto de habilidades cognitivas usadas para resolver problemas ou gerar soluções alternativas.

Corroborando com a definição de Cavallo et al. (2016) encontramos nesse processo de conceituação o que Torrance definiu como criatividade:

[...] o processo de tornar-se sensível a problemas, deficiências, lacunas no conhecimento, desarmonia; identificar a dificuldade, buscar soluções, formulando hipóteses a respeito das deficiências; testar e retestar estas hipóteses; e, finalmente, comunicar os resultados. (Torrance, 1976, p. 02).

Desse modo, ao nos sensibilizarmos com o problema vivenciado atualmente com o isolamento social e o fechamento das escolas, ocasionados pela pandemia da Covid-19, buscamos em meio a tantas dificuldades novas ações a fim de contribuir para a sociedade, 
fomentando uma prática pedagógica mais criativa. De acordo com Gardner (1996, p.36) "a criatividade não está somente na ideia, no processo ou na habilidade do artista, nem no domínio de prática e tampouco no grupo de juízes, mas sim numa interação entre todas essas dimensões".

De acordo com as pesquisas de Oliveira e Alencar (2012) a criatividade passou a despertar maior interesse por investigação após o discurso de Guilford (1950), ao assumir a presidência da Associação Americana de Psicologia, no qual declarou ser essa uma habilidade que precisaria ser reconhecida e desenvolvida, enfatizando sua importância para o indivíduo e a sociedade, sendo objeto de diversos estudos (Feldman, Csikszentmihalyi; Gardner, 1994; Amabile, 1996; Martínez, 1997; Wechsler,2002a; Alencar \& Fleith, 2003a; Lubart, 2007). Assim, estes e tantos outros pesquisadores endossam a importância de se cultivar o desenvolvimento das habilidades criativas para a atuação do ser humano na sociedade, representando um marco fundamental para resolver ou minimizar uma infinidade de problemas que possam causar entraves no contexto social e/ou educacional.

Neste contexto, justifica-se o crescente interesse pelas capacidades de inovação do ser humano, aumentando assim os estudos sobre a criatividade, onde as pesquisas relacionadas ao tema, realizadas nas décadas de 1970 e 1980, segundo Fleith (2001, p.55) "foram influenciadas especialmente pela psicologia cognitiva que procurava investigar os processos cognitivos e a influência do contexto social no desenvolvimento humano".

Para Lubart (2007) a combinação entre fatores pertencentes ao indivíduo e ao ambiente é necessário para o desenvolvimento da criatividade, ou seja, esta depende de fatores emocionais, cognitivos, conativos e ambientais, estando ambos relacionados entre si. Assim, os estímulos proporcionados no decorrer da disciplina de Interculturalidade foram importantes para desenvolver nosso processo criativo, nos envolvendo de forma engajadora nas atividades.

Dessa forma, é relevante que os profissionais da educação tenham este entendimento, em que incentivar o desenvolvimento de habilidades criativas seja a palavra de ordem, para que assim possamos alcançar o objetivo principal que é o de proporcionar à sociedade uma educação com maior qualidade e excelência.

\subsection{Prática pedagógica criativa}

No que concerne ao momento atual, ser criativo tornou-se uma necessidade que vai além dos muros da escola, necessitando que as práticas pedagógicas contemplem o desenvolvimento do pensamento criador. Segundo La Torre (2008) a criatividade é uma exigência social. Assim, de acordo com o autor:

[...] concluímos que a sociedade necessita e exige que, na renovação de metas educativas, seja instalado o desenvolvimento da criatividade, como norte e motor de novas orientações metodológicas. Já não se trata de uma qualidade rara e inalcançável para muitos..., mas sim da fonte de energia mais poderosa que a humanidade já imaginou (TORRE, 2008, p.25)

Muitas vezes a criatividade encontra-se adormecida dentro de cada um de nós, sendo necessário estímulo para despertá-la, o que tivemos bastante durante as aulas da disciplina Interculturalidade, nos possibilitando colocar em prática habilidades criativas tendo como aliadas às tecnologias digitais. Assim, de acordo com Oliveira e Alencar:

Com referência a esse ambiente, o professor constitui elemento chave para facilitar o desenvolvimento do potencial criador dos alunos. Para tanto, a escola precisa ser um espaço que cultive e valorize as ideias originais de seus educadores, oportunizando o desenvolvimento e o desabrochar de habilidades que muitas vezes esse profissional desconhece possuir. (OLIVEIRA; ALENCAR, 2012, p. 543) 
A disciplina Interculturalidade, ministrada de maneira criativa e engajadora, contribuiu para o desenvolvimento do potencial criativo do grupo ao proporcionar vivências que possibilitaram até mesmo despertar algumas habilidades desconhecidas. Partindo desse pressuposto, podemos entender que a diversidade de manifestações criativas explica as dezenas de definições para o termo criatividade. Apesar de apresentar significados distintos para diferentes pessoas, a criatividade pode ser definida segundo a visão de diversas disciplinas como negócios, ciências, música, artes plásticas, teatro, dança e arquitetura.

Ser criativo significa ser capaz de gerar novas ideias, que sejam úteis, e auxiliem na resolução dos problemas do cotidiano. Desse modo, a Base Nacional Comum Curricular (BNCC, 2017) nos traz, uma de suas competências, no que tange ao desenvolvimento do pensamento criativo:

\begin{abstract}
Exercitar a curiosidade intelectual e recorrer à abordagem própria das ciências, incluindo a investigação, a reflexão, a análise crítica, a imaginação e a criatividade, para investigar causas, elaborar e testar hipóteses, formular e resolver problemas e criar soluções (inclusive tecnológicas) com base nos conhecimentos das diferentes áreas. (BNCC, 2017, p. 09)
\end{abstract}

Em um futuro bem próximo, os indivíduos terão que aprender a sintetizar o conhecimento e expandi-lo de novas maneiras com as quais ainda não estão familiarizados. Gardner (2005), em seu livro: "Las cinco mentes del futuro", destaca os tipos de mentes que são imprescindíveis aos indivíduos. De acordo com o autor, a mente disciplinada utiliza os modos de pensar relacionados às principais disciplinas acadêmicas como história, matemática, ciências, arte e as principais profissões - direito, medicina, administração de empresas, economia, etc.; A mente sintética seleciona informações decisivas entre grandes quantidades de informações disponíveis, expõe as informações de uma maneira que faz sentido para si e para os outros; A mente respeitosa responde sistematicamente e construtivamente às diferenças entre indivíduos e entre grupos tentando entender e trabalhando com quem é diferente, indo além da mera tolerância e do que é politicamente correto; A mente ética procura distinguir as características essenciais do papel que se desempenha no trabalho e as que se exerce como cidadão, agindo de forma coerente com esses conceitos, esforçando para fazer um bom trabalho e exercer uma boa cidadania. Por último, mas não menos importante, a mente criativa, que busca ir além do conhecimento e da síntese existentes, colocando novas questões, propondo novas soluções, modelando obras, expandindo os gêneros existentes ou configurando novos. Nesta, a criatividade incorpora uma ou mais disciplinas estabelecidas e requer um campo informado para fazer julgamentos sobre a qualidade e a aceitabilidade da mesma. Assim, esse tipo de mente criativa é de fundamental relevância para educandos e educadores do século XXI.

Ser criativo, nas diversidades de situações que envolvem o processo de ensino e aprendizagem com todos os meios tecnológicos que concernem esse desenvolvimento e todas as situações adversas, se faz necessário.

\title{
3.3 Criatividade aliada às tecnologias digitais
}

Com o advento da pandemia da Covid-19, encontrar soluções em meio ao caos foi de suma importância e em meio a tentativas, com erros e acertos, a necessidade de lidar com o desconhecido fez com que os professores buscassem adaptar-se ao novo momento, adotando novas posturas, tendo nas tecnologias digitais uma forte aliada, porém muitos ainda não dominam o uso das mesmas, necessitando de buscarem qualificação para tal, o que encontramos não só na disciplina aqui relatada, mas em todo o curso de Mestrado. 
As tecnologias digitais representam ferramentas importantes na publicação, divulgação de tais ações pioneiras e de sucesso; que podem ser acessadas e reproduzidas entre seus pares nos mais variados ambientes de ensino.

Além disso, a necessidade de propiciar na escola um ambiente favorável ao desenvolvimento e à expressão da criatividade tem sido enfatizada por educadores de diversos países, tendo o professor um papel significativo nesse processo (Alencar, 2002). Nesse momento de reinvenção, as tecnologias digitais estão se destacando como importantes aliadas ao processo criativo. Assim, de acordo com Muguet et al::

A tecnologia multimídia cada vez mais vem sendo utilizada em salas de aula e tem evidenciado sua importância no campo educacional. Mas, se faz necessário que os docentes sejam capacitados para que façam uso corretamente das ferramentas tecnológicas. (MUGUET et al., 2020, p. 56)

Neste contexto, as tecnologias digitais estão presentes e ainda mais evidentes para ressignificar a prática docente, auxiliar e despertar a criatividade, tornando a educação do século XXI mais atraente para o aluno que nasce e cresce ambientado nessa era tecnológica. Desse modo, corroborado por Mendes e Santos, em recente publicação na edição especial da Revista Recite:

As transformações estão acontecendo, já se observa o primeiro passo na busca de soluções para que a educação não fique estagnada neste momento tão atípico, e que movimentos educacionais estão sendo feitos de modo que as novas tecnologias digitais possam trabalhar de forma alinhada com o ensino. Contudo muitos ajustes ainda deverão ser feitos. (MENDES; SANTOS, 2020, p. 105)

\subsection{O professor em sala de aula: uma necessidade criativa na pandemia}

O impacto causado pela pandemia de Covid-19 foi forte em vários aspectos na sociedade, e na esfera educacional não foi diferente. As escolas tiveram de fechar as portas, os alunos foram mandados para casa e o ensino presencial acabou de uma hora para outra, sendo transferido para um esquema de aulas remotas, amparadas pelo parecer do Conselho Nacional de Educação (CNE), sendo a seguir homologado pelo Ministério da Educação (MEC), a fim de cumprir carga horária mínima do calendário escolar e reorganizálo.

O ensino remoto, ofertado em diferentes plataformas durante esse período pandêmico, apesar das dificuldades de acesso à tecnologia evidenciando as desigualdades sociais existentes, viabilizou o cumprimento do calendário escolar, porém, transformou radicalmente o modo de trabalho dos professores em todo o Brasil, em que, de acordo com Martins e Almeida (2020, p.218) "a utilização dos artefatos tecnológicos na educação básica ganhou força com a pandemia de Covid-19".

Assim, com a utilização de aulas remotas, a oferta de materiais didáticos com o uso das tecnologias digitais, se tornou imprescindível, sendo os memes educativos, os vídeos, a gamificação, os debates nas redes sociais e as lives, exemplos de como o professor teve que se reinventar e ter na criatividade uma aliada na melhoria da qualidade do ensino ofertado. Para Trindade e Moreira (2021, p.76) "com alguma criatividade poder-se-á tirar partido de todos os recursos digitais que podem estar ao alcance dos estudantes e que podem ser associados a cada área disciplinar".

A velocidade da transformação jogou os educadores nessa nova realidade com pouquíssimo preparo. De acordo com Silva (2020, p.104) "no cotidiano escolar são usados diversos dispositivos digitais por discentes e docentes, porém, na maioria das vezes, eles não são potencializados pedagogicamente". Nesse momento em que as tecnologias digitais se fazem tão presentes, aproveitar ao máximo os recursos disponíveis se faz necessário à prática pedagógica. Assim, corroborado por Nakano (2009, p.49) "perante as dificuldades 
encontradas na prática profissional, reforça-se a importância do uso da criatividade como recurso auxiliar na resolução dos problemas encontrados no dia a dia da escola".

É uma situação tão séria que mesmo depois de tanto tempo após o início do isolamento, a grande maioria dos professores brasileiros continua se sentindo despreparado para a nova forma de ensino. Com a abertura gradual de escolas e a necessidade de um rodízio entre os alunos, outro modelo de ensino vem se desenhando no cenário educacional brasileiro: o ensino híbrido, que se caracteriza por envolver atividades presenciais e a distância. Assim, conforme Oliveira (2021, p.19) "nessa nova realidade cada vez mais híbrida e hiperconectada, torna-se necessário criar mecanismos de promoção, em professores e alunos, de competências e literacias digitais".

\section{ANÁLISE E DISCUSSÃO DOS RESULTADOS}

A disciplina Interculturalidade do Mestrado Profissional, nos proporcionou o convite à inquietude constante, o incentivo a pensar e criar soluções e caminhos através de produtos que possam viabilizar as problemáticas oriundas de grupos específicos da sociedade, de forma que o caminho constante rumo à excelência sejam ações cotidianas, gerando subsídios que possam resultar em uma educação com mais qualidade.

No que tange a escola, segundo Oliveira e Alencar (2012), esta passou a ser considerada como um dos contextos que influenciam no desenvolvimento da criatividade dos cidadãos, sendo assim importante e necessário rever as práticas pedagógicas para que estas sejam condizentes com um ambiente criativo. Portanto, um professor propiciador da criatividade está sempre revendo suas práticas e se reinventando a fim de promover 0 desenvolvimento da mesma em seus alunos, contribuindo significativamente para 0 processo ensino-aprendizagem.

Segundo La Torre (2005) a escola pode influenciar o desenvolvimento da capacidade inovadora e criativa dos alunos. No entanto, é fundamental observar a necessidade do estímulo de atitudes e habilidades criativas desde a educação infantil até a universidade, conscientizando-se o professor sobre a importância da inserção, em seu planejamento, de objetivos que visem potencializar a criatividade de seus alunos.

Ao buscarmos as pesquisas de alguns estudiosos, observamos nos estudos de Wechsler (2002b) uma análise dos resultados de diversos estudos brasileiros sobre a importância do desenvolvimento da criatividade no ambiente escolar, realizados com diferentes faixas etárias, que aponta não só a necessidade de formação do professor, mas também o despertar dos mesmos para suas próprias dificuldades, na prática pedagógica, como sendo desafios para a escola criativa. Corroborado pelos estudos de Oliveira e Alencar (2007) ao apresentar dados semelhantes a esses resultados, em que os empecilhos à criatividade mais mencionados pelos entrevistados foram relacionados à formação e atuação do professor, como, por exemplo, o ensino conteudista, tradicional e excessivamente teórico que receberam em sua formação.

Com base no exposto, torna-se necessário a atualização acadêmica no que se refere ao incentivo no desenvolvimento da criatividade nas áreas de ensino. Pois esta temática será determinante para a formação de profissionais mais capacitados e preparados para atender as demandas que estão surgindo e as que virão em um futuro bem próximo.

Apesar de termos caminhado tanto, temos a consciência de que ainda há um longo caminho a percorrer, porém o que fomenta essa busca constante de possibilidades, é a pesquisa contínua, a troca de experiências entre os pares, que resultam em ações 
educacionais de maior alcance a todos os envolvidos e a melhoria na qualidade profissional dos agentes e atores pertencentes à esfera acadêmica.

Observa-se, ainda, que o contexto atual é caracterizado pela utilização cada vez maior das tecnologias digitais, sendo um desafio a diversos setores da nossa sociedade. $\mathrm{Na}$ educação, esse uso vem de uma necessidade de educar os alunos para a sociedade do conhecimento, em que possam ser críticos e autônomos; trabalhar em colaboração; resolver problemas; comunicar-se com facilidade; reconhecer e respeitar a todos; e utilizar, intensa e extensivamente, as tecnologias digitais aliadas à sua criatividade, tendo na figura docente um incentivador. Assim, corroborado por Morán:

\begin{abstract}
Desafios e atividades podem ser dosados, planejados e acompanhados e avaliados com apoio de tecnologias. Os desafios bem planejados contribuem para mobilizar as competências desejadas, intelectuais, emocionais, pessoais e comunicacionais. Exigem pesquisar, avaliar situações, pontos de vista diferentes, fazer escolhas, assumir alguns riscos, aprender pela descoberta, caminhar do simples para o complexo. Nas etapas de formação, os alunos precisam de acompanhamento de profissionais mais experientes para ajudá-los a tornar conscientes alguns processos, a estabelecer conexões não percebidas, a superar etapas mais rapidamente, a confrontá-los com novas possibilidades. (MÓRAN, 2015, p.18)
\end{abstract}

Neste sentido, ao incorporar o uso das tecnologias digitais à prática pedagógica, estaremos proporcionando aos educandos desenvolvimento do seu potencial criativo, à medida que ele entra em contato com diferentes culturas, ter acesso ao que se está produzindo no Brasil e no mundo, ajudando a testar distintas possibilidades, podendo ainda refinar suas produções, estimular sua imaginação e o desenvolvimento de novas ideias, e até buscar comunicação imediata, sobre avaliação de suas produções e sugestões a elas, em um curto espaço de tempo (Valente, 2005; Loveless, 2007).

$O$ desafio de se reinventar tem sido um grande paradigma a ser transpassado pelos educadores e educandos. Agora, diante dessa necessidade rápida de transformação decorrente da ausência do espaço físico da sala de aula, a tecnologia digital tornou-se primordial para a manutenção da aprendizagem, assim como a criatividade. Desse modo, de acordo com Carvalho et al. (2021, p. 05) "os profissionais da educação precisam dominar o conhecimento e a informação como matérias primas enfrentando, dessa forma, os desafios oriundos das novas tecnologias".

É preciso continuar entregando conteúdos aos alunos, encontrar meios para manter um diálogo rico e vencer um grande desafio: manter a qualidade do processo de ensinoaprendizagem considerando todas as novidades e limitações desse período, em que ser criativo e utilizar tecnologias digitais, como aplicativos e plataformas, são tão necessários à prática docente.

Durante a disciplina Interculturalidade, vivenciamos na prática atividades com os seguintes temas: Entender e viver a arte, a cultura e estética; Art selfie; Autorretrato; Dar e receber presentes; A diversidade dos sentidos; Contar histórias; O desafio de comunicar em sala de aula e fora dela; Storytelling; Ética, estética e criatividade, e logo que nos foi proposto fazermos uma avaliação da disciplina, colocamos em prática o que aprendemos e relatamos, em uma live produzida por nós mesmos, essa experiência. A pergunta central da nossa live foi: Como foi o processo de aprendizado na disciplina de Interculturalidade para você? Relatamos, por meio da live intitulada "Relato de experiência Interculturalidade e a Educação do século XXI (2020)" disponibilizada no link https://youtu.be/va6Zpf9Z0jM as experiências que tivemos em aula e o quanto fomos criativos em cada uma delas.

Falamos, no decorrer da live, de todo carinho que aprendemos a ter pela professora, que já se apresentava muito dinâmica, desde o primeiro semestre, em outra disciplina. Citamos a experiência da aula com o tema: Dar um presente, que foi ministrada próximo ao dia dos professores, em que nos foi propostos criar um vídeo sobre a história de vida de 
um colega da turma e de como isso foi assertivo, já que além de relembrarmos nossa história na educação também ouvimos a de nossos amigos de classe, respectivamente sorteados e presenteados com esse vídeo cheio de amabilidade.

Pontuamos como a energia da professora é contagiante e a atividade do autorretrato nos fez olhar nossa imagem e perceber: Quem somos? Como estamos? Quais os nossos objetivos? O que estamos fazendo? Aflorando em nós a resiliência emocional. Falamos sobre estética e fomos levados a refletir sobre as particularidades de cada um e que não precisamos ficar presos a um padrão e que cada indivíduo, dentro das suas potencialidades, tem a contribuir com o outro e com a sociedade, valorizando assim a nossa autoestima, sendo as aulas envolventes e produtivas, nos fazendo superar nossas dificuldades em relação à imaginação criativa e às tecnologias digitais que precisávamos dominar, fazendo com que avançássemos em cada aula proposta.

Montarmos, fazermos o roteiro e efetivarmos essa live, criando esse produto tecnológico é a grande prova de como a criatividade, junto às tecnologias digitais são de grande relevância nesse momento de pandemia. $O$ engajamento foi visto tanto por parte da professora, quanto por parte dos alunos envolvidos na disciplina, em que fomos levados a refletir que nascemos com a criatividade e que muitas vezes pode estar adormecida dentro de nós, precisando apenas ser despertada.

Esse momento de pandemia está nos levando a essa abertura ao novo, a curiosidade para aprender e vamos levar esse despertar criativo não só para o campo profissional, mas para a vida.

\section{CONSIDERAÇÕES FINAIS}

Concluímos com esse estudo que estimular a criatividade por meio de atividades prazerosas utilizando as tecnologias digitais no decorrer das aulas ministradas na disciplina Interculturalidade foi de grande valia, principalmente por despertar em nós competências adormecidas, contribuindo para o desenvolvimento de nossas habilidades.

A ampliação da visão de mundo adquirida durante as aulas foi motivante e enriquecedora, despertando os sentidos por meio de propostas criativas que atingiram a todos de maneira significativa.

A criatividade faz-se muito necessária para a educação, pois através dela podemos afetar o outro positivamente. Esperamos, então, que a sociedade reconheça a importância de promover ambientes apropriados para o desenvolvimento da criatividade dos seus indivíduos, assim como os professores e os sistemas educativos levem em consideração a sua capacidade de influência para valorizar a criatividade de todos os envolvidos nos processos educacionais.

Nos dias de hoje, o pensamento criativo aliado às tecnologias digitais tornou-se de fundamental relevância para docentes e discentes, sendo imprescindíveis e de grande aplicabilidade para a educação no século XXI. Sem sombra de dúvidas, esta pode ser considerada uma parceria de sucesso na obtenção de bons resultados na práxis docente e consequentemente no processo ensino-aprendizagem. Afinal, o processo criativo incentiva a elaboração de estratégias pedagógicas diferenciadas e inovadoras, que podem aguçar o interesse dos alunos pelos mais variados conteúdos, resultando em um ambiente estimulador tanto para o professor quanto para o aluno.

Os conhecimentos obtidos acerca da criatividade podem contribuir para a implementação de procedimentos transformadores no contexto escolar que atenda às exigências que demandam a atual situação pandêmica a qual estamos vivenciando. 
Assim, espera-se que os resultados desse estudo possam oferecer sugestões para futuras discussões e pesquisas, colaborando para auxiliar no preenchimento de lacunas sobre estudos empíricos a respeito da importância da criatividade no contexto educacional em meio a pandemia, uma vez que esta não se expressa unicamente através de grandes feitos, mas também em todas as formas de ações inovadoras do ser humano, inclusive na resolução de problemas e questionamentos que surgem em seus diversos ambientes de atuação.

Por fim, a disciplina Interculturalidade foi o estopim inicial para se discutir sobre o tema e vislumbrar a necessidade criativa para atuações e interações do indivíduo dentro e fora dos muros da escola.

\section{REFERÊNCIAS}

ALENCAR, E. M. L. S. O contexto educacional e sua influência na criatividade. Linhas Críticas, 8 (15),165-178, 2002. Disponível em: https://periodicos.unb.br/index.php/linhascriticas/article/view/3055/2747. Acesso em: abr.2021.

ALENCAR, E. M. L. S.; FLEITH, D. S. Criatividade: múltiplas perspectivas. Brasília: Universidade de Brasília, 2003a.

AMABILE, T. M. Criatividade em contexto/ Creativity in context. Colorado: Westview Press, 1996.

BRASIL, Ministério da Educação. Base Nacional Comum Curricular. Brasília: MEC, 2017. Disponível em: http://basenacionalcomum.mec.gov.br. Acesso em: abr. 2021.

CAVALLO, David et al. Inovação e criatividade na educação básica: dos conceitos ao ecossistema. Revista Brasileira de Informática na Educação, v. 24, n. 02, p. 143, 2016. Disponível em: https://www.br-ie.org/pub/index.php/rbie/article/view/6504. Acesso em: abr. 2021.

CARVALHO, A C.dos et al. Tecnologias da informação e suas transformações na educação. Revista CPAQV-Centro de Pesquisas Avançadas em Qualidade de Vida| Vol, v. 13, n. 1, p. 2, 2021. Disponível em: https://www.researchgate.net/profile/AndersonCarvalho/publication/350568013 TECNOLOGIAS DA INFORMACAO E SUAS TRANS FORMACOES NA EDUCACAO Information technologies and their transformations in education/links/6066817ea6fdccad3f664dd4/TECNOLOGIAS-DA-INFORMACAO-ESUAS-TRANSFORMACOES-NA-EDUCACAO-Information-technologies-and-theirtransformations-in-education.pdf. Acesso em: abr. 2021.

DELORS, J. et al. Educação: um tesouro a descobrir: relatório para a UNESCO da Comissão Internacional sobre Educação para o Século XXI. Tradução: Guilherme João de Freitas Teixeira. São Paulo: Cortez; Brasília, DF: UNESCO, 2010. Disponível em:

FELDMAN, D. H.; CSIKSZENTMIHALYI, M.; GARDNER, H. Changing the world: a framework for the study of creativity. Westport: Praeger, 1994.

FLEITH, D. S. Criatividade: novos conceitos e ideias, aplicabilidade à educação.

Cadernos de Educação Especial, 17, 55-61, 2001. Disponível em: 
https://periodicos.ufsm.br/educacaoespecial/article/view/5229/3193. Acesso em: abr. 2021.

GARDNER, H. Mentes que criam. 1 ed., Porto Alegre: Artes Médicas, 1996.

GARDNER, H. Las cinco mentes del futuro, Paidós Artríticos, 2005.

GIL, Antônio Carlos. Como elaborar projetos de pesquisas. 4. ed. 11. reimpr. São Paulo: Atlas, 2010.

GUILFORD, J. P. Criatividade. Psicólogo americano/ Creativity. American Psychologist, $5,444-454,1950$

LA TORRE, D. E. S. Dialogando com a criatividade. São Paulo: Madras, 2005.

LA TORRE, S.; Criatividade aplicada: recursos para uma formação criativa. São Paulo, Madras, 2008.

LOVELESS, A. Literature review in creativity, new technologies and learning. 2007.

Disponível em: http://archive.futurelab.org.uk/resources/publications-reportsarticles/literature-reviews/Literature-Review382. [ Links ] Acesso em: abr. 2021

LUBART, T. Psicologia da criatividade. Porto Alegre: Artmed, 2007.

MARTÍNEZ, A. M. Criatividade, personalidade e educação. Campinas: Papirus, 1997.

MARTINS, V.; ALMEIDA, J.; Educação em Tempos de Pandemia no Brasil:

Saberesfazeres escolares em exposição nas redes. Revista Docência e Cibercultura, v. 4, n. 2, p. 215-224, 2020. Disponível em https://www.e-publicacoes.uerj.br/index.php/redoc/article/view/51026/34672 Acesso em: abr. 2021

MENDES, E. N.; SANTOS, L.; Aprender a aprender novas maneiras de ensinar. RECITE - Revista Carioca de Ciência, Tecnologia e Educação, Rio de Janeiro, v. 05, n. especial, 2020. Disponível em:

https://recite.unicarioca.edu.br/rccte/index.php/rccte/article/view/142 Acesso em: abr. 2021.

MENDES, E. N.; SANTOS, L.; ALMEIDA, T. A.; RODRIGUES, A.V.C. Relato de experiência Interculturalidade e a Educação do século XXI. Disponível em: https://youtu.be/va6Zpf9Z0jM, 2020. Acesso em: abr. 2021.

MINAYO, M. C. S. (Org.). Pesquisa social: teoria, método e criatividade. 18. ed. Petrópolis, RJ: Vozes, 2001. Disponível em:

https://pt.scribd.com/document/332436178/Pesquisa-Social-Teoria-Metodo-e-CriatividadeMaria-Cecilia-de-Souza-Minayo-org-18\%C2\%AA-edicao-pdf. Acesso em: mai. 2021.

MORÁN, J. Mudando a educação com metodologias ativas. In: Coleção mídias contemporâneas. Convergências midiáticas, educação e cidadania: aproximações jovens, v. 2, n. 1, p. 15-33, 2015. Disponível em: https://edisciplinas.usp.br/pluginfile.php/4941832/mod resource/content/1/ArtigoMoran.pdf Acesso em: mai. 2021. 
MUGUET, D. S. et al. Relato de experiência sobre a produção de vídeos para conjugação entre teoria e prática no ensino técnico em informática. Revista Carioca de Ciência, Tecnologia e Educação, Rio de Janeiro, v. 5, n 1, 2020. Disponível em: https://recite.unicarioca.edu.br/rccte/index.php/rccte/issue/view/8 Acesso em: abr. 2021.

NAKANO, T. C.; Investigando a criatividade junto a professores: pesquisas brasileiras. Psicologia escolar e educacional, v. 13, n. 1, p. 45-53, 2009. Disponível em: https://www.scielo.br/pdf/pee/v13n1/v13n1a06.pdf Acesso em: abr. 2021.

OLIVEIRA, E. B. P.; ALENCAR, E. M. L. S. Importância da criatividade na escola e no trabalho docente segundo coordenadores pedagógicos. Estudos de Psicologia I Campinas I 29(4) I 541-552 I outubro - dezembro 2012. Disponível em: https://www.scielo.br/pdf/estpsi/v29n4/v29n4a09.pdf. Acesso em: abr. 2021.

OLIVEIRA, E. S. G.(org.) O desafio da mediação tecnológica na nova normalidade educacional. Por uma educação para Polegarzinha. In: OLIVEIRA, Eloiza da Silva Gomes de Oliveira (org.). Ensinar e aprender com mediação das tecnologias no tempo de "novas normalidades": experiências e reflexões em variados cenários. Curitiba- PR: Bagai, 8-21, 2021. [livro eletrônico]

OLIVEIRA, Z. M. F.; ALENCAR, E. M. L. S. Criatividade na formação e atuação do professor do curso de letras. Psicologia Escolar e Educacional, 2, 2007, 223-237.

Disponível em: https://www.scielo.br/pdf/pee/v11n2/v11n2a04.pdf. Acesso em: abr. 2021.

SILVA, R. N. K. O perfil necessário ao professor frente à influência da cibercultura no contexto educacional. Revista Docência e Cibercultura, v. 4, n. 2, p. 103-118, 2020. Disponível em: https://www.epublicacoes.uerj.br/index.php/redoc/article/download/47919/34664. Acesso em: abr. 2021.

TRINDADE, S. D.; MOREIRA, J. A. Contributos para o design pedagógico de ambientes online na Educação Superior. In: Ensinar e aprender com mediação das tecnologias no tempo de "novas normalidades": experiências e reflexões em variados cenários [livro eletrônico] / organização Eloiza da Silva Gomes de Oliveira. - Led.- Curitiba- PR: Editora Bagai, 71-81, 2021.

VALENTE, J. A. Pesquisa, comunicação e aprendizagem com o computador: O papel do computador no processo ensino-aprendizagem. In: ALMEIDA, M. E. B. ; MORAN, J. M. (Eds.), Integração das tecnologias na educação (pp. 22-31). Brasília: MEC/SEED, 2005. Disponível em: https://cmapspublic.ihmc.us/rid=1HXFXQKSB-23XMNVQM9/VALENTE 2005.pdf. Acesso em: abr. 2021.

WECHSLER, S. M. Criatividade: descobrindo e encorajando. Campinas: Livro Pleno.2002a

WECHSLER, S. M. Criatividade e desempenho escolar: uma síntese necessária. Linhas Críticas, 8 (15),179-188, 2002b. Disponível em: https://periodicos.unb.br/index.php/linhascriticas/article/view/3056 Acesso em: abr. 2021. 